\title{
Analisis Gerakan Forehand Pada Tenis Meja Di Klub PTM Elektra Kab Demak
}

\author{
Dyah Ismi Mukaromah ${ }^{1}$, Husnul Hadi², Muh. Isna Nurdin ${ }^{3}$ \\ ${ }^{123}$ Universitas PGRI Semarang, Jl. Gajah Raya No.40 Semarang \\ Email: 18dyahismi@gmail.com
}

\begin{abstract}
The background is because the athlete only uses a forehand to defend, whereas a forehand is good for attacking. The formulation of the problem, how to analyze the biomechanics of forehand motion in table tennis and how good hand movements, body position and leg position using forehand movements, whether the 9 angles of the movement affect the entry or absence of the ball. The aim of this research is to know how the biomechanical analysis of forehand motion in table tennis and to find out how good hand movement, body position and leg position using the forehand movement of the 9 angles affect the entry or absence of the ball. Based on processing using statistics, there is a significant difference in comparisons when the ball position hits the bet; 1) wrist position $167.8750-223.80 ; 2$ ) bending of the right elbow 82,9o-92,1o; 3 ) bending of the left elbow 86.24o-95.82o; 4) opening of the upper arm of the right hand 71.06o-78.95o; 5) opening of the upper arm of the left hand 45.45o$50.5 \mathrm{o}$; 6) leaning body $145.54 \mathrm{o}-161.71 \mathrm{o}$; 7) right leg bending $152.60-169.50$; 9) distance of both feet 44.05o48.94o.
\end{abstract}

Keywords: Forehand, Table Tennis.

\begin{abstract}
ABSTRAK
Latar belakang karena atlet hanya menggunakan pukulan forehand untuk bertahan, padahal pukulan forehand bagus untuk menyerang. Rumusan masalah, bagaimana analisis biomekanika gerakan forehand pada cabang olahraga tenis meja dan bagaimana gerakan tangan, posisi badan dan posisi kaki yang baik dengan menggunakan gerakan forehand apakah dari 9 sudut gerakan tersebut mempengaruhi masuk atau tidaknya bola. Tujuan penelitin ingin mengetahui bagaimana analisis biomekanika gerakan forehand pada cabang olahraga tenis meja dan untuk mengetahui bagaimana gerakan tangan, posisi badan dan posisi kaki yang baik dengan menggunakan gerakan forehand apakah dari 9 sudut gerakan tersebut mempengaruhi masuk atau tidaknya bola.Berdasarkan pengolahan dengan menggunakan statistik, terdapat perbedaan perbandingan yang signifikan saat posisi bola mengenai bet; 1) posisi pergelangan tangan $167,875^{\circ}-223,8^{\circ}$; 2) tekukan siku kanan $82,9^{\circ}-92,1^{\circ}$; 3) tekukan siku kiri $86.24^{\circ}$ $95.82^{\circ}$; 4) bukaan lengan atas tangan kanan $71,06^{\circ}-78,95^{\circ}$; 5) bukaan lengan atas tangan kiri $45,45^{\circ}-50,5^{\circ} ; 6$ ) kecondongan badan $145,54^{\circ}-161,71^{\circ}$; 7) tekukan kaki kanan $152,6^{\circ}-169,5^{\circ}$; 9) jarak kedua kaki $44,05^{\circ}-48,94^{\circ}$.
\end{abstract}

Kata kunci: Forehand, Tenis Meja. 


\section{PENDAHULUAN}

Tenis meja merupakan salah satu cabang olahraga yang sudah dikenal dan digemari banyak orang. Mulai dari usia anak - anak sampai dewasa bahkan orang tua. Hal ini mebuktikan bahwa tenis meja telah bermasyarakat, bahkan kejuaraan tenis meja yang bersifat umum dan terbuka sering diadakan pada suatu acara tertentu. Perkembangan permainan tenis meja di Indonesia cukup menggembirakan akhir akhir ini. Di tinjau dari segi kuantitas hampir seluruh lapisan masyarakat telah mengenal tenis meja dan mampu untuk memainkannya. Dari kejuaraan yang bersifat umum, hampir seluruh daerah yang mengikutinya. Ini membuktikan bahwa tenis meja Indonesia sudah mampu menempati posisi di tingkatan yang menggembirakan, baik di Asia Tenggara maupun di Asia, bahkan di tingkat dunia. Ini membuktikan Indonesia mempunyai potensi untuk menyiptakan atlet tenis meja yang handal. Indonesia baru mengenal tenis meja sejak tahun 1930, dan baru terorganisasi tahun 1958, yaitu berdirinya persatuan Tenis Meja Seluruh Indonesia.

Tenis meja adalah suatu cabang olahraga memukulkan atau mengembalikan bola di atas meja permainan dengan menggunakan bet yang kemudian dipantulkan ke arah bidang meja lawan dimainkan oleh dua orang yang saling berlawanan dan dengan melewati net. Tujuan dari olahraga ini yaitu dengan cara dimainkan diatas meja yang berbentuk persegi dengan panjang meja 2,74 $\mathrm{m}$, lebar meja 1,525 m, tinggi meja $76 \mathrm{~cm}$ dengan net setinggi $15,25 \mathrm{~cm}$ yang terbuat dari bahan nilon. Cabang olahraga tenis meja ada 7 nomor atau partai yang dipertandingkan dalam kejuaraan tenis meja Indonesia maupun Dunia. Partai yang dipertandingan dalam olahraga tenis meja yaitu beregu putra, beregu putri, ganda putra, ganda putri, ganda campuran, tunggal putra dan tunggal putri.

Proses latihan dalam memperlajari keterampilan teknik pada permainan tenis meja menggunakan metode pengamatan dan dipelajari secara berulang-ulang dengan mengunakan contoh atlet yang memainkan permainan tenis meja yang sangat bagus atau sudah mencapai level tertinggi dalam pertandingan. Seperti yang diutarakan oleh Sudarto (2009:26) "Metode latihan yang mendasari berhasilnya bentuk ketrampilan teknik yaitu metode latihan langsung (direct practice method) dan tidak langsung (indirect practice method)."

Teknik dasar tenis meja harus benar - benar dikuasai karena, teknik dasar merupakan suatu modal awal seorang pemain untuk mengembangkan bakat dalam cabang olahraga mana pun. Dalam olahraga tenis meja ada beberapa macam teknik pukulan yang berfungsi untuk mengembalikan bola ke daerah lawan agar menghasilkan poin. Pukulan pada olahraga tenis meja meliputi teknik pukulan drive, push, tospin, block, chop, smash dan service. Dari berbagai teknik tenis meja, di golongkan menjadi teknik pukulan bertahan, teknik pukulan serang dan teknik pukulan servis. Kelompok teknik pukulan bertahan meliputi pukulan push dan pukulan blok, sedangkan teknik pukulan serang meliputi pukulan topspin dan pukulan smash. 
Keterampilan teknik pukulan yang paling dominan digunakan atlet serta paling kuat dalam melakukan smash yaitu teknik forehand yang mana merupakan teknik yang paling kuat, selain itu tenaga yang digunakan lebih maksimal dari pada pukulan backhand dan dipergunakan untuk menyerang lawan terdapat dalam teknik forehand yaitu teknik forehand drive, teknik ini merupakan teknik yang paling sering digunakan untuk melakukan serangan kepada lawan bermain. Selain forehand drive ada beberapa ketrampilan teknik lain yang terdapat dalam teknik forehand tersebut yaitu forehand push, forehand chop, forehand block, forehand spin. Tidak jauh berbeda dengan backhand juga mempunyai beberapa macam pukulan sama seperti teknik pukulan yang ada dalam ketrampilan teknik forehand seperti backhand drive, backhand push, backhand chop, backhand block, backhand spin dan teknik gerak kaki serta taktik untuk meraih kemenangan dalam tiap permainan tenis meja (Mahendra, dkk. 2012:12).

Fungsi pukulan forehand pada permainan tenis meja lebih besar di bandingkan degan pukulan backhand. Dari hasil wawancara dengan pelatih bahwa "beberapa atlet yang sudah bisa melakukan gerakan forehand kebanyakan enggan melakukan gerakan tersebut karena dalam pelaksanaanya sangat menguras energi dan konsentrasi” tutur Bu Nisa. Klub PTM Elektra Kab Demak sebelumnya beranggotakan 30 atlet sekarang menjadi 25 atlet, sebab kebanyakan masih berusia belia sedangkan di usia ini masih banyak keingin tahuan terhadap sesuatu, mencoba hal baru dan cepat bosan. Dalam tes ketepatan gerakan forehand beberapa atlet dalam pelaksanaannya ada yang sudah menguasai dan ada yang belum bisa diantaranya:

Tabel 1. Kelompok usia atlet yang tidak dan menguasai pukulan forehand

\begin{tabular}{lcc}
\hline $\begin{array}{c}\text { Kelompok } \\
\text { Usia } \\
\text { Atlet }\end{array}$ & $\begin{array}{c}\text { Jumlah } \\
\text { Atlet }\end{array}$ & $\begin{array}{c}\text { Menguasai } \\
\text { Gerakan }\end{array}$ \\
\hline SD & 13 & 7 \\
\hline SMP-SMA & 12 & 6 \\
\hline JUMLAH & 25 & 13 \\
\hline
\end{tabular}

Ketika observasi peneliti mengamati atlet dalam melakukan gerakan forehand ada beberapa atlet yang power nya kurang dan gagal atau bola mati. Semua atlet masih duduk di bangku sekolah yang terkadang mengganggu para atlet untuk latihan, hal ini mengharuskan para atlet untuk lebih pintar membagi waktu supaya pendidikan dan prestasi menjadi atlet sama-sama baik. Hal ini yang mendasari sehingga peneliti mengangkat judul "Analisis Gerakan Forehand Pada Tenis Meja Di Klub PTM 
Elektra Kab Demak". Adanya judul di atas peneliti ingin supaya para atlet dapat melakukan gerakan forehand dengan lebih baik dari sebelumnya dan pelatih dapat mengajarkan anak didiknya dengan gerakan yang baik dan nyaman dilakukan oleh atlet itu sendiri, sehingga para atlet dapat berprestasi dengan maksimal.

\section{METODE PENELITIAN}

Metode penelitian menggunakan metode kualitatif. Populasinya yaitu atlet klub PTM Elektra Kab Demak. Sampel penelitian adalah 10 atlet yang telah menjuarai minimal 3 kompetisi tingkat kecamatan. Analisis data yang akan diambil dalam penelitian ini berupa video pukulan forehand cabor tenis meja, pengambilan video diambil sesuai dengan instrument yang penelitian buat untuk memudahkan proses analisis. Setelah pengambilan video selesai data dianalisis dengan perangkat lunak software dartfish, untuk menjawab rumusan masalah penelitian.

Langkah-langkah penelitian kualitatif adalah reduksi, display data, dan yang terakhir adalah kesimpulan/verifikasi (Sugiyono, 2017: 337) :

\section{a) Redukis Data}

Reduksi data berarti merangkum, memilih hal-hal yang pokok, merupakan memfokuskan pada halhal yang penting, dicari tema dan polanya dan membuang yang tidak perlu. Dengan demikian data yang sudah direduksi akan memberikan gambaran yang lebih jelas, dan mempermudah peneliti untuk untuk melakukan pengumpulan data selanjutnya dan mencarinya bila diperlukan.

b) Data Display (Penyajian Data)

Display data merupakan langkah sesudah data direduksi. Dalam penelitian kualitatif, penyajian data bisa dilakukan dalam bentuk uraian singkat, bagan, hubungan antar kategori flowchart dan sebagainya. dan yang paling sering digunakan untuk menyajikan data dalam penelitian kualitatif adalah dengan teks yang bersifat naratif.

c) Penarikan Kesimpulan

Kesimpulan/verifikasi merupakan langkah terakhir setelah mendisplay data. Kesimpulan dalam penelitian kualitatif mungkin dapat menjawab rumusan masalah yang dirumuskan sejak awal, tetapi mungkin juga tidak, karena seperti telah dikemukakan bahwa masalah dan rumusan masalah dalam penelitiian kualitatif masih bersifat sementara dan akan berkembang setelah penelitian berada di lapangan.

\section{HASIL PENELITIAN}

Hasil dari penelitian analisis gerak teknik forehand pada tenis meja di klub PTM Elektra Kab Demak yang telah dilakukan memberikan gambaran bagaimana cara melakukan gerakan pukulan forehand dari mulai gerakan persiapan, backswing, forwardswing, impact dan gerakan followthrough 
yang baik dilihat dari 9 item sudut yang dianalisis yaitu sudut pergelangan tangan, sudut tekukan siku kanan, sudut tekukan siku kiri, sudut bukaan lengan atas tangan kanan, sudut bukaan lengan atas tangan kiri, sudut kecondongan tubuh, sudut tekukan kaki kanan, sudut tekukan kaki kiri, dan bukaan kaki saat melakukan teknik pukulan forehand.

Berdasarkan data yang diperoleh lalu di analisis dan dibandingkan oleh peneliti hasil rata-rata percobaan pukulan atlet ke-1 sampai atlet ke-10 menghasilkan pukulan pertama masuk sedangkan percobaan pukulan kedua atau ketiga beberapa menghasilkan bola keluar, dilihat di tabel berikut ini:

Tabel 2. Hasil analisis pukulan masuk dan pukulan tidak masuk

\begin{tabular}{lcc}
\hline \multicolumn{1}{c}{ SIKAP } & $\begin{array}{c}\text { SUDUT PUKULAN } \\
\text { MASUK }\end{array}$ & $\begin{array}{c}\text { SUDUT PUKULAN } \\
\text { TIDAK MASUK }\end{array}$ \\
\hline Pergelangan Tangan & $167.875^{\circ}$ & $140.6^{\circ}$ \\
\hline Siku Tangan Kanan & $82.9^{\circ}$ & $76.88^{\circ}$ \\
\hline Siku Tangan Kiri & $86.24^{\circ}$ & $68.025^{\circ}$ \\
\hline Bukaan Lengan Kanan & $71.06^{\circ}$ & $72.4^{\circ}$ \\
\hline Bukaan Lengan Kiri & $45.45^{\circ}$ & $58.9^{\circ}$ \\
\hline Kecondongan Badan & $145.54^{\circ}$ & $140.76^{\circ}$ \\
\hline Tekukan Kaki Kanan & $152.6^{\circ}$ & $146.54^{\circ}$ \\
\hline Tekukan Kaki Kiri & $149.7^{\circ}$ & $148.64^{\circ}$ \\
\hline Jarak Kedua Kaki & $44.05 \mathrm{~cm}$ & $46.3 \mathrm{~cm}$ \\
\hline
\end{tabular}

Dari data yang didapat menunjukkan bahwa terjadi perbedaan yang signifikan, rata-rata pukulan masuk siku membentuk sudut kira-kira $82.9^{\circ}$ dan pukulan keluar membentuk sudut kira-kira 76.88 . Wisnu Adi menyatakan dalam tesisinya yang berjudul "Teknik Dasar Tenis Meja” bahwa ratarata siku membentuk sudut kira-kira $90^{\circ}$.

Hal ini dapat menunjukkan bahwa pentingnya keseimbangan pergelangan,siku tangan, rotasi badan dan kaki. Penting bagi pelatih untuk memperhatikan semua faktor tersebut, sehingga ketika atlet sudah memasuki golden age, maka perbedaan tidak terlalu jauh bahkan bisa menghasilkan bola masuk dan memiliki power yang maksimal agar sulit diterima oleh lawan.

\section{KESIMPULAN}

Berdasarkan hasil penelitian yang dilakukan terdapat beberapa simpulan dari hasil analisis data yang dilakukan. Terdapat selisih 9 sudut gerakan yang dilakukan oleh sampel, sehingga ini dapat memberikan dampak yang sangat berpengaruh terhadap hasil dari pukulan forehand yang dilakukan oleh sampel. Dalam melakukan persiapan hingga gerakan akhir, selain faktor pergerakan tangan, faktor tumpuan badan dan tekukan kaki jam terbang megikuti kompetisi menjadi salah satu faktor yang tidak 
bisa dipisahkan supaya atlet bisa memotifasi dirinya agar atlet dapat menghasilkan gerakan yang maksimum.

Didalam penelitian ini kelihatan sekali perbedaan sudut yang dihasilkan. Hal ini dapat menjadikan salah satu koreksi para pelatih untuk memperhatikan atletnya ketika melakukan pukulan, agar kebiasaan sejak dini sudah dibentuk menjadi kebiasaan yang baik, kelemahan ini dapat diperbaiki dengan memberikan latihan dasar-dasar pukulan forehand, pada saat melakukan dasar-dasar pukulan pelatih harus memperhatikan secara detail gerakan yang dilakukan oleh atletnya agar atlet tidak melakukan gerakan yang salah.

\section{DAFTAR PUSTAKA}

Abdurrhamat, Asep Suryana. (2011). Analisis Biomekanika Pukulan Forehand Pada Olahraga Tenis. Tesis. Universitas Negeri Gorontalo.

Aedi, Nur. (2010). Instumrn Penelitian Dan Pengumpulan Data. Tesis. Universitas Pendidikan Indonesia.

Ardiyanto, Hysa \& Widiyanto. (2019). Prinsip-Prinsip Biomekanika Kualitatif: Upaya Menjembatani Teori dan Aplikasi dalam Sport Science. Tesis. Yogyakarta: Universitas Negeri Yogyakarta.

Arikunto \& Sugiyono, dkk. (2018). Pengertian Instrumen Penelitian Menurut Para Ahli. Diambil dari: https://www.zonareferensi.com/pengertian-instrumen-penelitian/.

Aziz, Nur. dkk. (2017). Analisis Gerakan Tendangan Shooting Futsal Pada Atlet Futsal UKM UPGRIS. Tesis. Semarang: Universitas PGRI Semarang.

Erman. (2009). Metodologi Penelitian Olahraga. Surabaya. Unesa University Press

Hidayat, R. Yulia Ratimiasih, dan Agus Wiyanto. (2018). Analisis Gerakan Lari Sprint 40 Meter Pada Mahasiswa UPGRIS. Tesis. Semarang: Universitas PGRI Semarang.

Hodges, Larry. (2007). Tenis Meja: tingkat pemula. Buku. Jakarta: PT RajaGrafindo Persada.

Kertamanah, Alex. (2015). Teknik Dan Taktik Tenis Meja. Bandung : PT. Remaja Rosdakarya.

Mahendra, Ika Rudi. Prapto Nugroho, dan Said Junaidi. (2012). Kelentukan Pergelangan Tangan dan Koordinasi Mata Tangan Dalam Pukulan Forehand Tenis Meja. Tesis. Semarang: Universitas Negeri Semarang.

Nugroho, Untung. (2015). Analisis Biomekanika Forehand Groundstruke Atlet Yunior Daerah Istimewa Yogyakarta. Tesis. Balai Kambang Surakarta: Universitas Tunas Pembangunan.

Rihtiana, Verandita \& Tomoliyus. (2014). Pengembangan Instrumen Penilaian Ketrampilan Teknik Forehand Dan Backhand Drive Tenis Meja Pada Atlet Usia Dini. Tesis. Yogyakarta: Universitas Negeri Yogyakarta.

Sadarmada, N \& Wijaya, IMK. (2015). Biomekanika Olahraga. Buku. Yogyakarta: Graha Ilmu. 
Sudarto. (2009). Pengaruh Metode Latihan Dan Waktu Reaksi Terhadap Keterampilan Drive Tenis Meja (Studi Eksperimen Perbedaan Pengaruh Metode Messed Practice dan Distributed Practice Pada Siswa Ekstrakurikuler Tenis Meja SMK Negeri 1 Trucuk Tahun Ajaran 2009/2010). Tesis. Surakarta. Program Universitas Sebelas Maret Surakarta.

Sugiyono. (2014). Statistika untuk Penelitian. Bandung: Alfabeta.

Sugiyono. (2015\&2016). Metode Penelitian Dan Pengembangan (Research and Development/ R\&D). Buku. Bandung: Alfabeta.

Sugiyono. (2017). Metode Penelitian Pendidikan. Bandung: Alfabeta. 